\title{
CO2 capture through electro-conductive adsorbent using physical adsorption system
} for sustainable development

\author{
Farooq, M.; Saeed, M. A.; Imran, M.; Uddin, G. M.; Asim, M.; Bilal, H.; Younas, M. R.; Andresen, J. M.
}

\section{Published in:}

Environmental Geochemistry and Health

Link to article, DOI:

$10.1007 / \mathrm{s} 10653-019-00318-2$

Publication date:

2020

Document Version

Peer reviewed version

Link back to DTU Orbit

\section{Citation (APA):}

Farooq, M., Saeed, M. A., Imran, M., Uddin, G. M., Asim, M., Bilal, H., Younas, M. R., \& Andresen, J. M. (2020). $\mathrm{CO}_{2}$ capture through electro-conductive adsorbent using physical adsorption system for sustainable development. Environmental Geochemistry and Health, 42, 1507-1515. https://doi.org/10.1007/s10653-01900318-2

\section{General rights}

Copyright and moral rights for the publications made accessible in the public portal are retained by the authors and/or other copyright owners and it is a condition of accessing publications that users recognise and abide by the legal requirements associated with these rights.

- Users may download and print one copy of any publication from the public portal for the purpose of private study or research.

- You may not further distribute the material or use it for any profit-making activity or commercial gain

- You may freely distribute the URL identifying the publication in the public portal 


\title{
$\mathrm{CO}_{2}$ Capture through Electro-conductive Adsorbent using Physical
}

\section{Adsorption System for Sustainable Development}

\author{
M. Farooq ${ }^{1,2}$, M. A. Saeed ${ }^{3}$ M. Imran,, G. M. Uddin', M. Asim ${ }^{2}$, H. Bilal, M. R. \\ Younas $^{6}$, J. M. Andresen ${ }^{1}$ \\ ${ }^{1}$ Research Centre for Carbon Solutions, Heriot-Watt University United Kingdom. \\ ${ }^{2}$ Department of Mechanical Engineering, University of Engineering and Technology Lahore \\ ${ }^{3}$ Department of Chemical and Polymer Engineering, University of Engineering and \\ Technology, Lahore, (Faisalabad Campus) \\ ${ }^{4}$ Department of Mechanical Engineering, Technical University of Denmark, Denmark \\ ${ }^{5}$ Australian Centre for Microscopy and Microanalysis, The University of Sydney, Australia \\ ${ }^{6}$ School of Engineering (SEN) University of Management and Technology (UMT) Lahore
}

\begin{abstract}
:
The most critical energy and environmental challenge that our planet is facing today is to minimize the dependence on fossil fuels. Carbon dioxide may be of utmost significance as a solution of this issue through realization of carbon neutral energy cycle. Potentially, this could be achieved through the carbon dioxide capture as the urgent response to ongoing climate change. Activated carbon (AC) adsorption is one the most effective, environment friendly and techno-economic process for the carbon capture. In the current research, an electro-conductive activated carbon was prepared by mixing powdered activated carbon (PAC) with an electro conductive polymer (ECP). Different ratios of 0, 25, 50, 75 and 100 wt. \% of ECP with PAC were used for the different analysis of activated carbons in a gas mixture of $\mathrm{CO}_{2} / / \mathrm{N}_{2}$ using a physical adsorption system. Adsorption and desorption analyses, capacities of the process and desorption effects were examined. Electro conductive polymers (ECP) were mixed with AC samples, where breakthrough time was increased up to $400 \%$ when mixed with the PAC for $\mathrm{CO}_{2}$ adsorption. Following adsorption analysis, desorption of activated carbons was conducted with different potentials. It was revealed that mixing could help the PAC sample to overcome the packing issue to increase the breakthrough capacity and the volumes before and after the breakthrough adsorption in the packed bed systems. The desorption rates of the PAC sample were also enhanced, and fast desorption was observed when mixed with ECP. It is envisioned that this method is very much promising carbon capture method for the techno-economic feasibility and sustainable development of the environment.
\end{abstract}

Key Words: Activated carbon, Carbon capture, Electroconductive polymers, Physical adsorption, sustainable development

*Corresponding author. Tel +923324418760

Email address: engr.farooq@uet.edu.pk/mf181@hw.ac.uk (Dr. M. Farooq) 


\section{Introduction}

Due to the more than $39 \%$ increase in atmospheric $\mathrm{CO}_{2}$ the average global temperature has risen to $0.8{ }^{\circ} \mathrm{C}$ during the past century. According to an estimate, the equivalent $\mathrm{CO}_{2}$ concentration in the atmosphere reaching to about $1600 \mathrm{ppm}$, the green-house gases has emissions would rise from $30-90 \%$ over the level of 2000 within next 10 years i.e. by the end of 2030. $\mathrm{CO}_{2}$ is also deemed to intensify the contamination of $\mathrm{CO}$, apart from its importance as GHG, when both exist in the same gas (Derakhshan-Nejad, Sun et al. 2019). Hence, the apprehensions regarding GHG emissions have triggered massive interest in exploring the domain of $\mathrm{CO}_{2}$ capture to deal with the environment and sustainability issues (Yang, Lee et al. 2017). Increase in $\mathrm{CO}_{2}$ causes stress on earth's climactic system and one of the most feasible method recognized up till now to reduce this stress is carbon capture technology (Choi, Piao et al. 2017, Saeed, Farooq et al. 2019).

The commercial technologies used for carbon capture are mainly absorptive and adsorptive processes, as well as processes based on membrane filtration or cryogenic separation (Wang, Yu et al. 2016, Bogusz, Oleszczuk et al. 2017, Budhathoki, Ajayi et al. 2019, Wilberforce, Baroutaji et al. 2019). These established techniques are facing significant challenges in terms of energy consumption and operating costs, which may add substantial costs as well (Thrän, Billig et al. 2014, Kougias, Treu et al. 2017).

The water scrubbing method is currently the most commonly used method for carbon capture (Farooq, Chaudhry et al.). The driving force for water scrubbing is operational track record and ease of use, while its main issue is high operating costs and water consumption (Rajendran, Browne et al. 2019). Pressure swing adsorption (PSA) is an efficient method, but its operational and capital costs are very high (Bauer, Persson et al. 2013). Separation of gases by membrane is a safe and efficient method and its cost are not high, but it has regenerative, scale-up and operational issues (Díaz et al., 2015, (Farooq, Qamar et al. 2016, Zhang, Xin et al. 2019). Membrane-based gas separation have typically low capital cost for the gas permeation processes (Scholz, Melin et al. 2013). Membranes have expensive operation and maintenance cost (Ryckebosch, Drouillon et al. 2011). Membrane based separation tends to be more costeffective in manufacturing relatively low-purity products. A summary of the techno-economic analysis for producing 97\% methane at 99\% recovery has been described by Shao et al. (Shao, Dal-Cin et al. 2012). Cryogenic systems are efficient and environment friendly, but these are costly because of the complex set-up to gain the required cryogenic conditions and used only 
at very large-scale industrial plants, since cost and safety is a main concern (Farooq, Almustapha et al. 2018, Song, Liu et al. 2019).

Adsorption by activated carbon, on the other hand, provides environment friendly solutions with reference to safety, applicability, and low energy use (Jayawardhana, Mayakaduwa et al. 2017, Rostami, Anbaz et al. 2018). Activated carbons are less costly comparison with silica, zeolite and alumina. The problems associated with activated carbon is the slow regeneration, which leads to high operational cost (Wang, Yao et al. 2016). Also, due to the pressure drop of powdered activated carbons (PAC) in the packed beds, it is recommended that PACs could be added with some other materials/ binders. It could be used with mixing to avoid the pressure drop issue (Bandosz 2006). A conductive material addition is suggested which could be helpful, as conductive polymers are cheaper.

Normally, at industrial level the exhaustive adsorbent is replaced with the fresh adsorbent (Farooq 2018). Presenting a cost-effective system for ACs as analysed by this paper could improve the application of AC to a greater extent. Since the activated carbon is a moderate conductive material, a low volt potential system could be helpful to disturb the adsorption forces between the adsorbate and the gas molecules, which could lead to fast desorption.

In the present study, the adsorption and desorption analysis of $\mathrm{CO}_{2}$ were conducted using

physical adsorption system. Repeated adsorption and desorption cycles with $\mathrm{CO}_{2}$ were conducted to establish breakthrough times, adsorption/desorption volumes and capacities of electro-conductive activated carbons, where the desorption was carried out with low electric potentials of 10, 20 and $30 \mathrm{~V}$ and compared without potential system. The results revealed that this system helped for the enhanced adsorption and fast desorption compared to the conventional system and accessible $\mathrm{CO}_{2}$ adsorption sites could be regenerated with desorption time shorter than the adsorption breakthrough time. Also, the adsorption and desorption cycles can be obtained with a classical two column system, which could lead towards a more efficient process.

\section{Material Characteristics}

Table 1 summarise the characteristics of activated carbon sample, which were conducted for surface area, elemental, proximate analysis and conductivity. The electro-conductive activated carbon was prepared by mixing the powdered activated carbon (PAC) sample with the electro- 
conductive polymer (ECP). The PAC is a steam activated carbon with the high filtration characteristics. It is produced under highly controlled conditions to insure consistent quality. The electro-conductive polymer (ECP) is a permanently electrically conductive thermoplastic based low-density polyethylene (LDPE) blends with different amounts of poly (ethylene-vinyl acetate) (EVA).

Table 1 Characteristics of powdered activated carbon

\begin{tabular}{|c|c|c|}
\hline \multirow{2}{*}{$\begin{array}{l}\text { Property } \\
\text { BET Surface area }\end{array}$} & \multicolumn{2}{|c|}{ Activated carbon } \\
\hline & $\left(\mathrm{m}^{2} / \mathrm{g}\right)$ & 758 \\
\hline Micropore volume $^{\mathrm{b}}$ & $\left(\mathrm{cm}^{3} / \mathrm{g}\right)$ & 0.169 \\
\hline Average pore radius ${ }^{\mathrm{c}}$ & (A) & 12.913 \\
\hline Micropore area ${ }^{a}$ & $(\%)$ & 66.6 \\
\hline Mesoporous area ${ }^{a}$ & $(\%)$ & 33.2 \\
\hline Macro pore area ${ }^{a}$ & $(\%)$ & 0.2 \\
\hline Carbon & $(\%)$ & 81.38 \\
\hline Hydrogen & $(\%)$ & 0.2 \\
\hline Nitrogen & $(\%)$ & 0.11 \\
\hline Oxygen ${ }^{d}$ & $(\%)$ & 0.71 \\
\hline Moisture content & $(\%)$ & 0.9 \\
\hline Volatile matter & $(\%)$ & 2.2 \\
\hline Fixed carbon & $(\%)$ & 80.3 \\
\hline Ash content & $(\%)$ & 16.7 \\
\hline \multicolumn{3}{|c|}{${ }^{\mathrm{a}}$ Measure from adsorption isotherm } \\
\hline \multicolumn{3}{|c|}{${ }^{b}$ Measured by application of $t-p l o t$} \\
\hline
\end{tabular}

\section{Experimental procedure}

The activated carbon sample was mixed with electro conductive polymers (ASTM method) to observe the effect of mixing of electro conductive polymers with the activated carbon. The $\mathrm{CO}_{2}$ adsorption and desorption analyses with the activated carbon samples were conducted in a packed bed of electro-conductive activated carbon as shown in Figure. 1. Glass wool was used 
at the bottom to avoid the adsorbent slippage, whereas, the filter paper was used at the top because of smooth passage of the gas in the bed. The gas manifold system comprises of different lines each fitted with volume flowmeters ranging from 1 to $100 \mathrm{Nml} / \mathrm{min}$. The system was equipped with a mass-spectrometer with the mass-soft for the continuous gas analyzing. Concentration of the carbon dioxide and nitrogen was analyzed before and after the activated carbon rig.

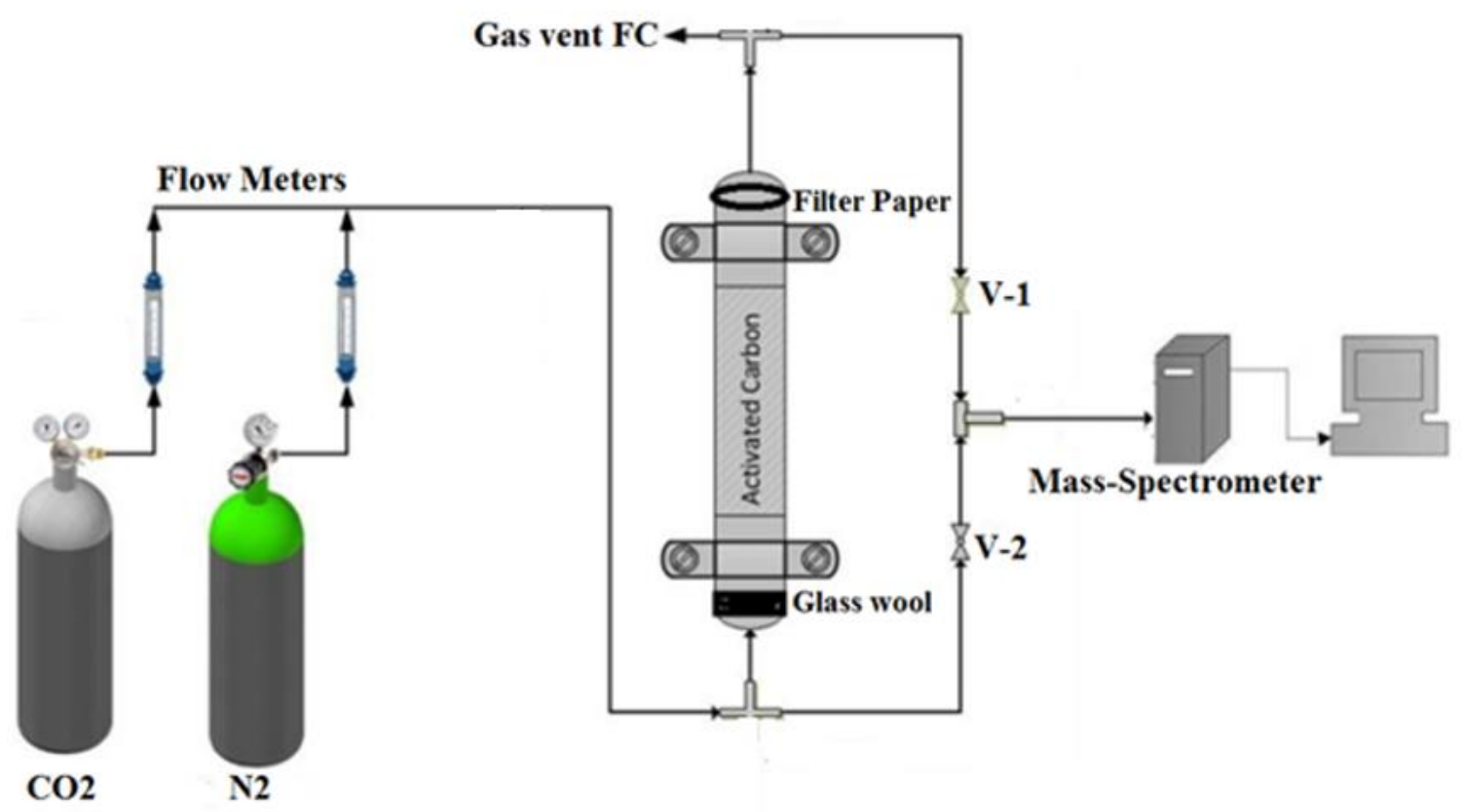

Figure 1. Experimental setup of Physical Adsorption System (Farooq, Bell et al. 2017) [modified from author's own experimental set-up]

\section{Results and Discussions}

\subsection{Effect of $\mathrm{CO}_{2}$ Adsorption on PAC sample with mixing ratios of 0, 25, 50, 75 and $100 \%$ with ECP}

Figure 2 compares the PAC adsorption with different mixing ratios of $0,25,50,75$ and $100 \%$ with the ECP. Breakthrough capacities of these mixing ratios were calculated, and adsorption behaviour was analysed. It was observed that the breakthrough time for the PAC sample without mixing is about 50 seconds. The adsorption curve raised fast and reached at $20 \%$ carbon dioxide after 95 seconds. Afterwards, adsorption was comparatively slow, and 90\% concentration was achieved after about 250 seconds, which is about 5 times slower than the initial 50\% adsorption. After this, 75\% PAC was mixed with 25\% ECP and the same adsorption 
process was repeated to observe the adsorption and breakthrough behaviour for the mixed sample. It was observed that the breakthrough time of the adsorption is 3.5 times longer than the PAC without mixing. After the breakthrough point, adsorption curve increased smoothly and 50\% adsorption was achieved in 147 seconds, i.e. 3.2 times higher compared with the PAC100 sample. Accordingly, the adsorption cycle was carried out by mixing $50 \%$ electro conductive polymer with PAC, which shows an increase in the breakthrough time as 5.4 and 1.5 times than PAC100 and PAC75ECP25, respectively. Overall adsorption trend of this mixing ratio sample was observed very much similar to that of PAC75ECP25. The PAC sample was further mixed with a ratio of PAC $25 \%$ with $75 \% \mathrm{ECP}$, which shows $6 \%$ increased breakthrough time compared to the $50 \%$ ratio. Adsorption process was then observed for the electro conductive polymers, which shows a breakthrough time of $272 \pm 43$ seconds, which is 8, 2.7, 1.5 and 1.4 times more than the PAC100, PAC75ECP25, PAC50ECP50 and PAC25ECP75, respectively. This shows that a direct increase in the breakthrough time of the PAC with the addition of ECP, which greatly helped to increase the adsorption rate in the packed bed.

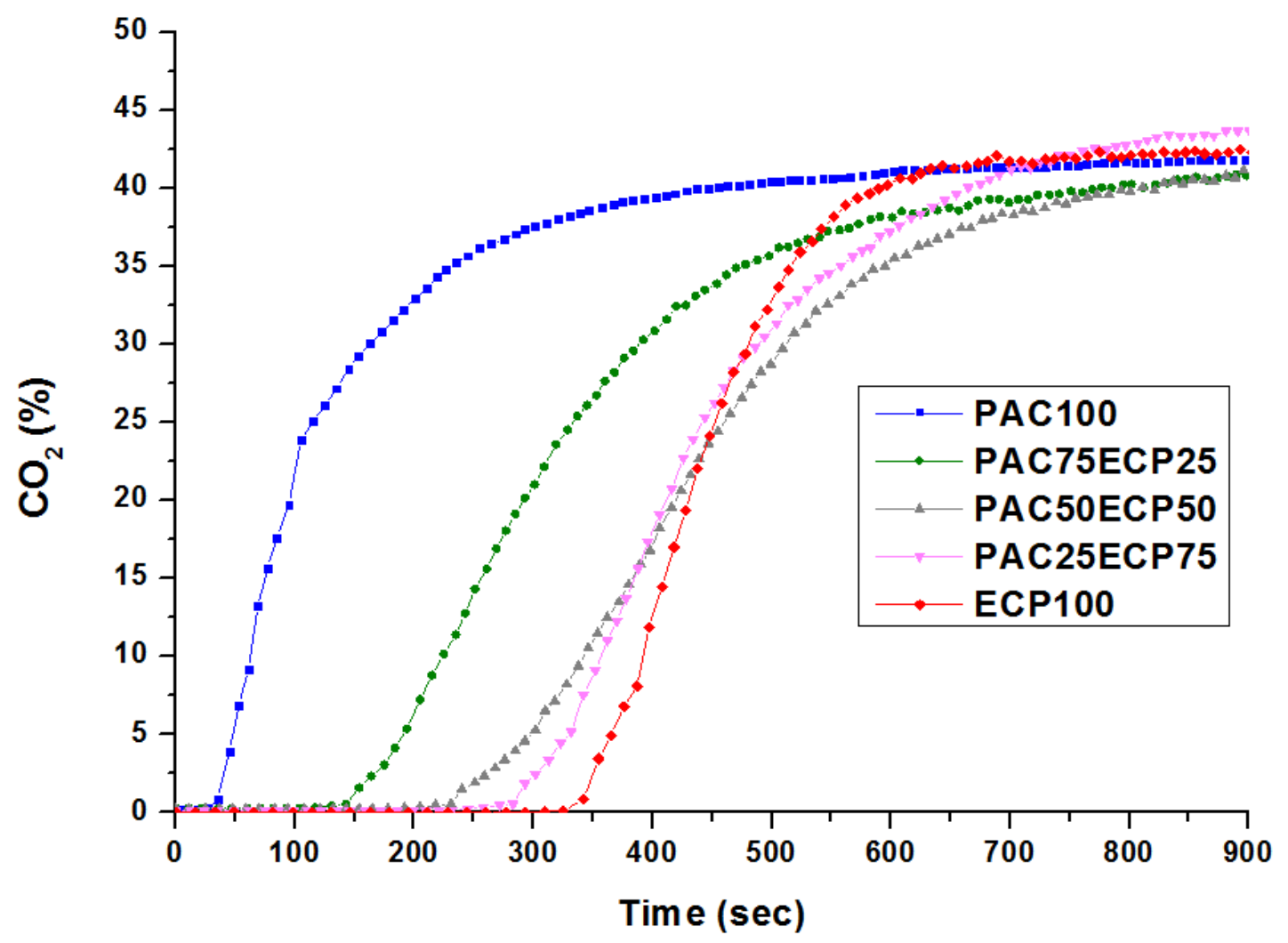

Figure 2 Effect of PAC adsorption at mixing ratios of 0, 25, 50, 75 and $100 \%$ with the ECP 


\subsection{Effect of adsorption breakthrough time of PAC mixing with ECP (wt. \%)}

Figure 3 compares the effect of adsorption breakthrough time of the PAC with different mixing ratios of the ECP from $0-100 \%$ with an increase of $25 \%$. First point was taken from the PAC adsorption breakthrough curve, which gave a value of $40 \pm 10$ seconds. With the addition of $25 \%$ ECP with $75 \%$ PAC sample, the adsorption breakthrough time increased to 143 seconds, which is about $3.5 \%$ than the PAC 100\% sample. The direct relation graph value should give a time of about 100 seconds, whereas, it was observed $43 \%$ higher value of adsorption time than the predicted linear relation. Analysis were continued with addition of further $25 \%$ of ECP sample in PAC with 50-50\% of PAC and ECP, which enhanced the adsorption breakthrough time to 201 seconds. Repetition of the experiments with the same ratios, give very smooth values of $201 \pm 17$, which improved the breakthrough 5.4 times than the PAC without mixing sample. The PAC sample was further mixed as PAC25ECP75, which shows consistency of increased breakthrough time of 231 seconds, which is about $8 \%$ longer. Further analysis was continued with ECP with $100 \%$ concentration which gives the breakthrough time as $272 \pm 43$ seconds. Since, the adsorption experiments were repeated over the different cycles, which gives good confidence level for the results. It shows very good linear relationship, which means that addition of the ECP with the PAC helps greatly to enhance the breakthrough time of the 
powdered sample. The synergistic effect for the total adsorbed volume has been elaborated in the next section with the comparison of different mixing of the PAC with ECP.

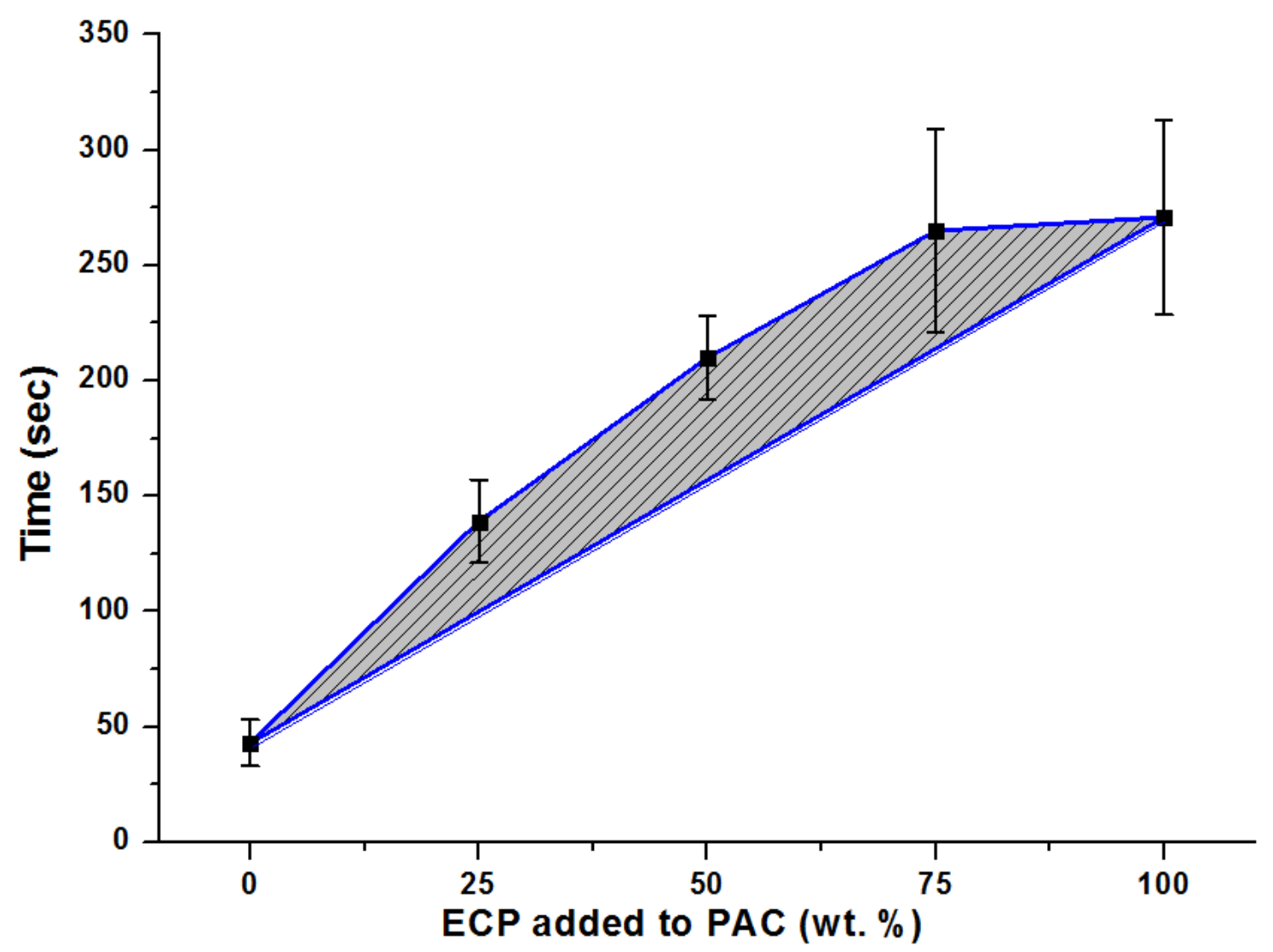

Figure 3 Effect of adsorption breakthrough time of the PAC with ECP

\subsection{Comparison of $\mathrm{CO}_{2}$ adsorption breakthrough time, volume, capacities, volume and synergistic effect of the PAC mixing with ECP}

Table 2 compares the breakthrough time (B.T.), capacities, adsorption volumes, theoretical calculated volumes and synergistic effect of volume of the PAC sample mixed with different ratios of the ECP. Breakthrough volumes of adsorption gives very smooth increased values with the mixing of ECP in the PAC sample. The total theoretical breakthrough volume was calculated about $42 \mathrm{~mL}$, whereas, adsorption volume was observed as $49 \mathrm{~mL}$, which gives a 17 vol. \% higher value. Subsequently, breakthrough volume for PAC50ECP50 was observed as $78 \mathrm{~mL}$, which is 4 times more than PAC100. The theoretical breakthrough volume for this ratio was calculated as $67 \mathrm{~mL}$, gives about $17 \%$ synergistic effect, which is very good outcome with the addition of ECP in the PAC sample. Accordingly, ECP sample was further $25 \%$ added in PAC sample, and the breakthrough volume for PAC25ECP75 was observed $83 \mathrm{~mL}$, with an increase of $6 \%$ than PAC50. The theoretical calculated breakthrough volume was $8 \mathrm{~mL}$ higher than the total adsorption volume with a synergistic effect of $9.2 \%$. It gives a clear depiction of 
smooth incremental values of the rig adsorption capacity and volumes at different ratios. This means that $25 \%$ and $50 \%$ ratio have a good compatibility of the particle connection, which covers a reasonable space for bonding the particles. The normalized rate of desorption could be helpful to further explain the behaviour of the mixing of ECP with PAC.

The observed data corresponds to the experimental results, whereas the calculated data related to the actual calculations of ECP and/or AC sample(s) as it is. The total rig adsorption of PAC/ECP sample is $0.1 \%$ higher than the ECP. It shows that the mixing of the ECP with the PAC results in good synergistic results compared to as its own. Since, PAC has good surface area and porous structure, which results in low adsorption due to pressure drop in the packed column. The addition of ECP with the PAC helped to regain its actual capacity.

Table 2 Adsorption time, volume, breakthrough capacities and synergistic effect of PAC mixing with ECP

\begin{tabular}{|c|c|c|c|c|c|c|c|}
\hline & Parameter & & $\begin{array}{l}\text { PAC } \\
100\end{array}$ & $\begin{array}{l}\text { PAC75 } \\
\text { ECP25 }\end{array}$ & $\begin{array}{l}\text { PAC50 } \\
\text { ECP50 }\end{array}$ & $\begin{array}{l}\text { PAC25 } \\
\text { ECP75 }\end{array}$ & $\begin{array}{l}\text { ECP } \\
100\end{array}$ \\
\hline \multirow{4}{*}{ 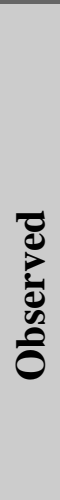 } & B.T. Time & $(\mathrm{sec})$ & 53.0 & 143.0 & 218.0 & 231.0 & 271.0 \\
\hline & B.T. Vol. & $(\mathrm{ml})$ & 17.5 & 49.2 & 77.7 & 83.0 & 116.0 \\
\hline & $\begin{array}{l}\text { Vol. after } \\
\text { B.T. }\end{array}$ & $(\mathrm{ml})$ & 56.5 & 68.4 & 92.8 & 63.4 & 49.0 \\
\hline & Total Vol. & $(\mathrm{ml})$ & 74.0 & 117.6 & 170.5 & 146.4 & 165.0 \\
\hline \multirow{5}{*}{ 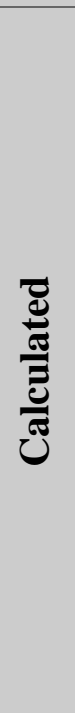 } & $\begin{array}{l}\text { Theoretical } \\
\text { B.T. Vol }\end{array}$ & $(\mathrm{ml})$ & 17.5 & 42.1 & 66.8 & 91.4 & 116.0 \\
\hline & B.T. Ads. & (wt.\%) & 0.4 & 1.0 & 1.5 & 1.6 & 2.3 \\
\hline & $\begin{array}{l}\text { Ads. After } \\
\text { B.T }\end{array}$ & (wt.\%) & 1.1 & 1.3 & 1.8 & 1.2 & 1.0 \\
\hline & Rig. Ads. & (wt.\%) & 1.5 & 2.3 & 3.3 & 2.9 & 3.2 \\
\hline & $\begin{array}{l}\text { Synergistic } \\
\text { Effect of B.T. }\end{array}$ & (Vol. \%) & 0.0 & 16.8 & 16.4 & -9.2 & 0.0 \\
\hline
\end{tabular}




\subsection{Effect of $\mathrm{CO}_{2}$ desorption profiles on $\mathrm{PAC}$ with mixing ratios of 0, 25, 50, 75 and $100 \%$ with ECP}

Figure 4 (a) and (b) compares the effect of desorption and normalized rate of desorption profile, respectively, for the PAC sample with different mixing ratios of $0,25,50,75$ and $100 \%$ with ECP, respectively. The $90 \%$ desorption of the PAC sample without any mixing of ECP was observed about 4 times longer compared with the $50 \%$ desorption. With the mixing of electro conductive polymer in the powdered sample helped to quick desorption, where by the addition of $25 \%$ ECP with $75 \%$ PAC reduced the $90 \%$ desorption to about half of the non-mixed PAC sample. After the observation of efficient behaviour of quick desorption mixing ratio was increased as $50-50 \%$ to observe the desorption behaviour, which shows $7 \%$ reduction at $50 \%$ desorption. However, with the 50-50\% mixing ratio, $90 \%$ normalized rate of desorption of mixed sample was observed 4.3 times fast than the PAC75ECP25. Further mixing of sample was observed as PAC25ECP75, which shows $21 \%$ quick desorption at the rate of $50 \%$ desorption compared with the previous mixing of 50-50\%. At the $90 \%$ normalized rate of desorption for this mixed sample, $40 \%$ efficient desorption was observed when compared with the PAC50ECP50 sample. Finally, the samples were compared with the ECP, which gives a very good direct linear relationship, and it was observed as almost 2.1 and 1.9 times fast desorption for 50 and $90 \%$ normalized rate of desorption, respectively. Since, in the current section the normalized rate of desorption of the different mixing ratios of ECP with PAC sample were analysed, it may be important to observe the behaviour of the normalized rate of desorption profiles of these mixing ratios with different low potentials. 

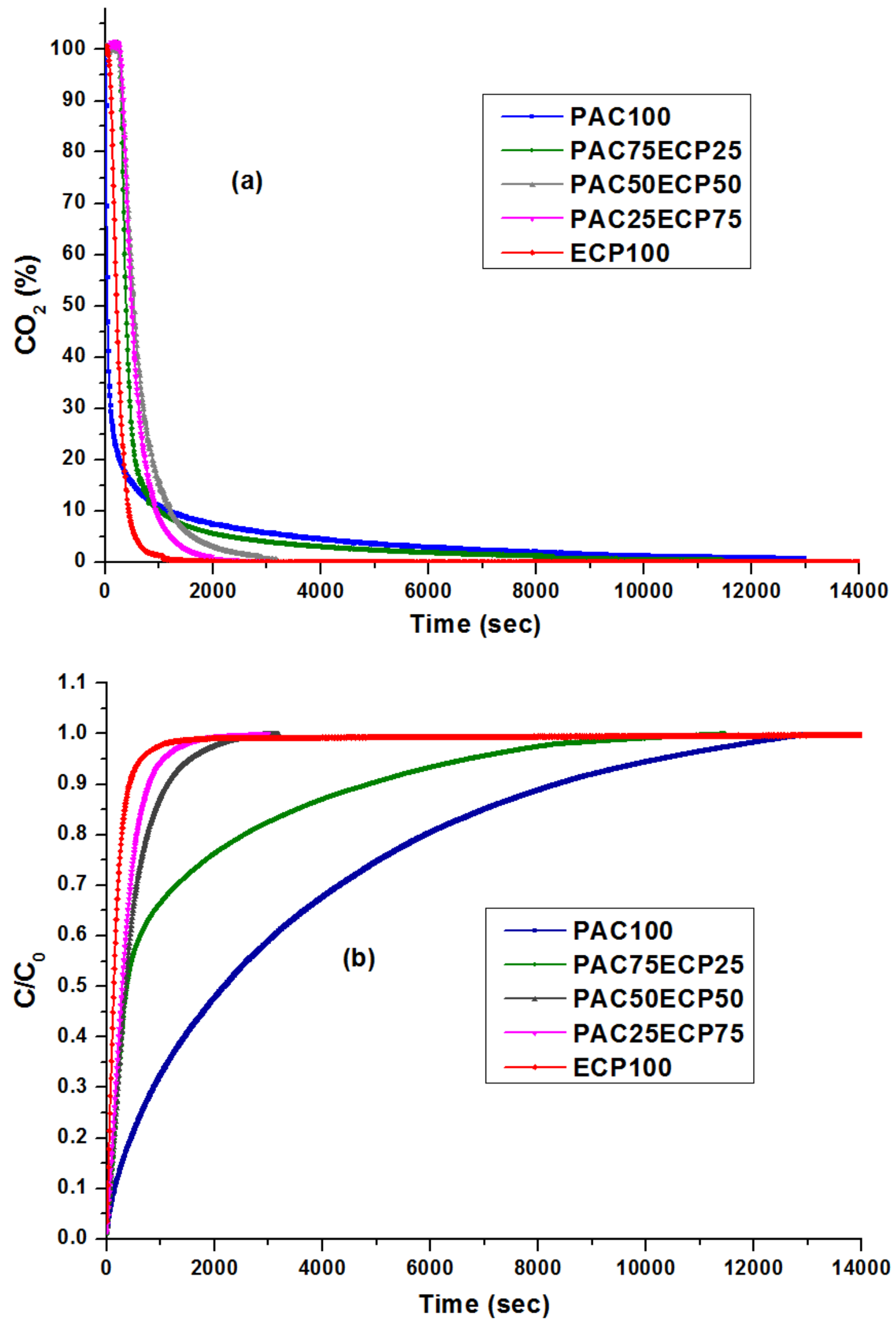

Figure 4 Mixing of PAC at ratios of 0, 25, 50, 75 and 100\% with ECP (a) Effect of desorption (b) Profiles of normalized rate of desorption 


\subsection{Effect of $90 \%$ desorption reduction of 0 and $30 \mathrm{v}$ potential for PAC sample at mixing ratios of $0,25,50,75$ and $100 \%$ with $\mathrm{ECP}$}

Figure 5 and Table 3 compares the effect of reduction of $90 \%$ desorption of 0 and $30 \mathrm{~V}$ potential of PAC with mixing ratios of 0, 25, 50, 75 and 100\% with ECP. The $90 \%$ desorption of the PAC sample occurred at about 8,277 seconds without mixing. This time was reduced to 4,425 seconds with the $30 \mathrm{~V}$ potential value, which is about $47 \%$ reduction in the desorption time. When the PAC sample was mixed with $25 \% \mathrm{ECP}$, a decrease of about $38 \%$ reduction was observed. This value found with similar linear behaviour, which was observed $25 \%$ for the 50 $50 \%$ mixing ratio of PAC with ECP. With an increase in the ECP ratio to $75 \%$ in overall weightage of the sample, the reduction in desorption was observed as $15 \%$. Whereas, without any mixing, ECP100 sample had the lowest value of $4.4 \%$. This behaviour of PAC shows a very smooth linear change in the sample with the ECP addition. However, there was no reasonable synergy observed.

Table 3 Effect of 90\% desorption time of PAC mixing with ECP at 0, 10, 20 and 30V

\section{potential}

\begin{tabular}{|l|l|l|l|l|}
\hline Sample & $\begin{array}{l}\text { Des. time } \\
\text { at 0V }\end{array}$ & $\begin{array}{l}\text { Des. time } \\
\text { at 10V }\end{array}$ & $\begin{array}{l}\text { Des. time } \\
\text { at 20V }\end{array}$ & $\begin{array}{l}\text { Des. time } \\
\text { at 30V }\end{array}$ \\
\hline PAC100 & $(\mathrm{sec})$ & $(\mathrm{sec})$ & $(\mathrm{sec})$ & $(\mathrm{sec})$ \\
\hline PAC75ECP25 & 4877 & 5029 & 4788 & 4425 \\
\hline PAC50ECP50 & 1113 & 4181 & 3860 & 3173 \\
\hline PAC25ECP75 & 788 & 967 & 965 & 833 \\
\hline ECP100 & 496 & 672 & 672 & 673 \\
\hline
\end{tabular}




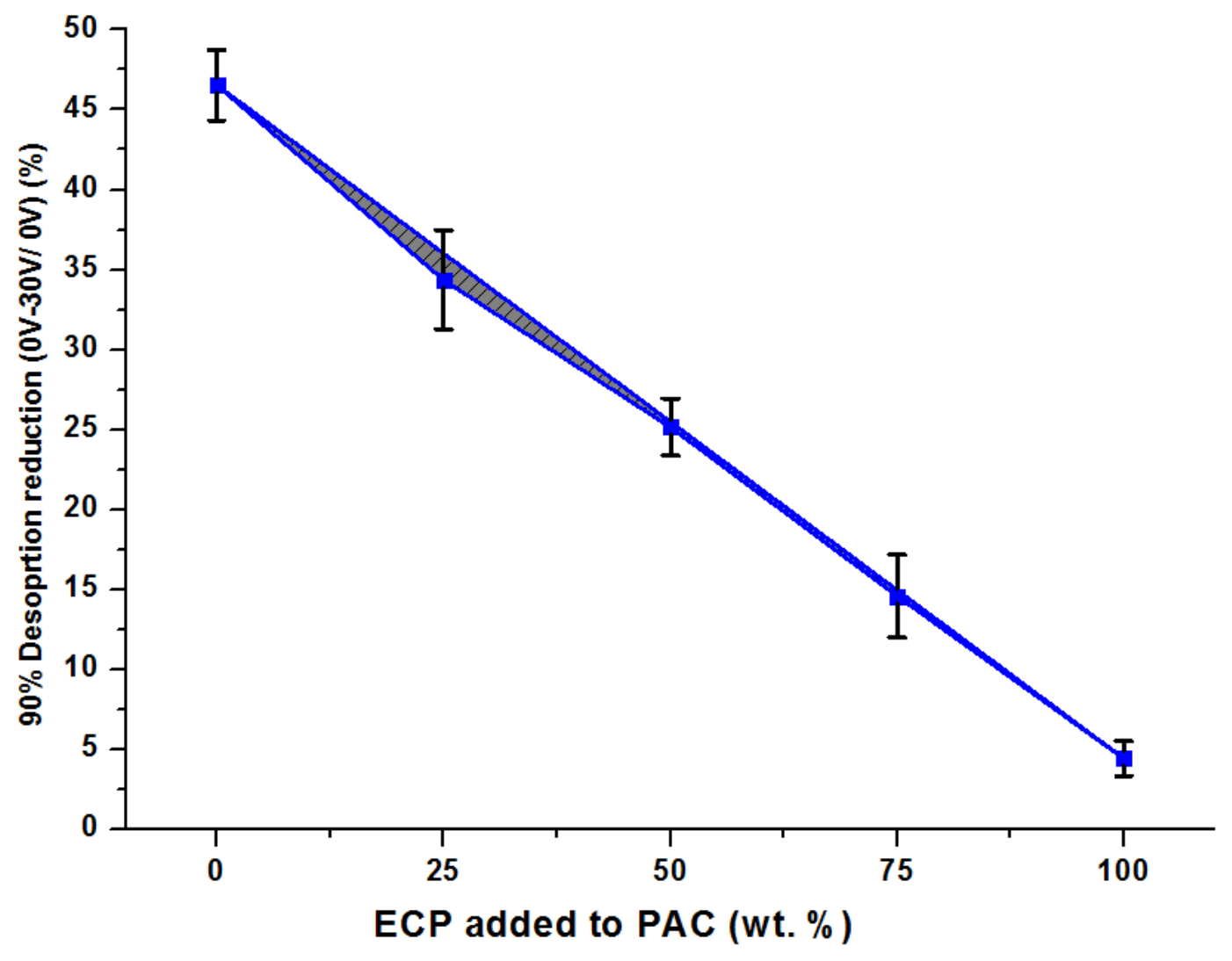

Figure 5 Effect of 90\% desorption reduction of PAC mixing with ECP from 0 to $30 \mathrm{~V}$ potential

\section{Conclusions}

It was concluded that the powdered activated carbon sample could be more effective for the adsorption and regeneration using physical adsorption system when used by adding with electro-conductive polymer. The electro-conductive polymers (ECP) used at different mixing ratios with the PAC shows very efficient results with increased breakthrough times compared with the non-mixed sample. Mixing ratio of ECP at 25\%, 50\% and $75 \%$ boosted the breakthrough times with $170 \%, 311 \%$ and $336 \%$ for the PAC sample. The synergistic effect was observed as $17 \%$ and $16 \%$ higher with $25 \%$ and $50 \%$ for the PAC sample, respectively. It is therefore concluded that adsorption and desorption of $\mathrm{CO}_{2}$ using physical adsorption system through electro-conductive activated carbon is a new way of adsorption and regeneration of adsorbent as compared to the system without potential. It is cost effective, safe and environment friendly. It can be used for quicker desorption of powdered activated carbon without using a pressure or temperature intensive techniques of regeneration, since regeneration can be done without the addition of any extra energy into the system.

\section{Acknowledgment}


1st author indebted to the support of UET Lahore and Higher Education Commission of Pakistan, for providing funding for the research grant.

\section{7. $\quad$ References}

Bandosz, T. J. (2006). Activated carbon surfaces in environmental remediation, Elsevier.

Bauer, F., T. Persson, C. Hulteberg and D. Tamm (2013). "Biogas upgrading-technology overview, comparison and perspectives for the future." Biofuels, Bioproducts and Biorefining 7(5): 499-511.

Bogusz, A., P. Oleszczuk and R. Dobrowolski (2017). "Adsorption and desorption of heavy metals by the sewage sludge and biochar-amended soil." Environmental geochemistry and health: 1-12.

Budhathoki, S., O. Ajayi, J. A. Steckel and C. E. Wilmer (2019). "High-throughput computational prediction of the cost of carbon capture using mixed matrix membranes." Energy \& Environmental Science.

Choi, H., J. Piao, N. C. Woo and H. Cho (2017). "Hydrochemical variations in selected geothermal groundwater and carbonated springs in Korea: a baseline study for early detection of $\mathrm{CO}_{2}$ leakage." Environmental geochemistry and health 39(1): 109-123.

Derakhshan-Nejad, Z., J. Sun, S.-T. Yun and G. Lee (2019). "Potential CO 2 intrusion in nearsurface environments: a review of current research approaches to geochemical processes." Environmental geochemistry and health: 1-26.

Farooq, M. (2018). "biogas upgardation for pakistan selected region ".

Farooq, M., M. Almustapha, M. Imran, M. Saeed and J. M. Andresen (2018). "In-situ regeneration of activated carbon with electric potential swing desorption (EPSD) for the H2S removal from biogas." Bioresource technology 249: 125-131.

Farooq, M., A. H. Bell, M. Almustapha and J. M. Andresen (2017). "Bio-methane from anaerobic digestion using activated carbon adsorption." Anaerobe 46: 33-40.

Farooq, M., I. Chaudhry, S. Hussain, N. Ramzan and M. Ahmed "Biogas up gradation for power generation applications in Pakistan."

Farooq, M., A. Qamar, M. Asim, F. Siddiqui, M. Amjad and A. Yousaf (2016). "Design and Analysis of Packed Bed Activated Carbon Reactor for the Enrichment of Biogas." University of Engineering and Technology Taxila. Technical Journal 21(1): 58.

Jayawardhana, Y., S. Mayakaduwa, P. Kumarathilaka, S. Gamage and M. Vithanage (2017). "Municipal solid waste-derived biochar for the removal of benzene from landfill leachate." Environmental geochemistry and health: 1-15. 
Kougias, P. G., L. Treu, D. P. Benavente, K. Boe, S. Campanaro and I. Angelidaki (2017). "Ex-situ biogas upgrading and enhancement in different reactor systems." Bioresource Technology 225: 429-437.

Rajendran, K., J. D. Browne and J. D. Murphy (2019). "What is the level of incentivisation required for biomethane upgrading technologies with carbon capture and reuse?" Renewable Energy 133: 951-963.

Rostami, A., M. A. Anbaz, H. R. E. Gahrooei, M. Arabloo and A. Bahadori (2018). "Accurate estimation of $\mathrm{CO} 2$ adsorption on activated carbon with multi-layer feed-forward neural network (MLFNN) algorithm." Egyptian Journal of Petroleum 27(1): 65-73.

Ryckebosch, E., M. Drouillon and H. Vervaeren (2011). "Techniques for transformation of biogas to biomethane." Biomass and bioenergy 35(5): 1633-1645.

Saeed, M. A., M. Farooq, G. E. Andrews, H. N. Phylaktou and B. M. Gibbs (2019). "Ignition sensitivity of different compositional wood pellets and particle size dependence." Journal of environmental management 232: 789-795.

Scholz, M., T. Melin and M. Wessling (2013). "Transforming biogas into biomethane using membrane technology." Renewable and Sustainable Energy Reviews 17: 199-212.

Shao, P., M. Dal-Cin, A. Kumar, H. Li and D. P. Singh (2012). "Design and economics of a hybrid membrane-temperature swing adsorption process for upgrading biogas." Journal of membrane science 413: 17-28.

Song, C., Q. Liu, S. Deng, H. Li and Y. Kitamura (2019). "Cryogenic-based CO2 capture technologies: State-of-the-art developments and current challenges." Renewable and Sustainable Energy Reviews 101: 265-278.

Thrän, D., E. Billig, T. Persson, M. Svensson, J. Daniel-Gromke, J. Ponitka, M. Seiffert, J. Baldwin, L. Kranzl and F. Schipfer (2014). "Biomethane-status and factors affecting market development and trade." IEA Task 40.

Wang, M., L. Yao, J. Wang, Z. Zhang, W. Qiao, D. Long and L. Ling (2016). "Adsorption and regeneration study of polyethylenimine-impregnated millimeter-sized mesoporous carbon spheres for post-combustion CO 2 capture." Applied Energy 168: 282-290.

Wang, T., W. Yu, F. Liu, M. Fang, M. Farooq and Z. Luo (2016). "Enhanced CO2 absorption and desorption by monoethanolamine (MEA)-based nanoparticle suspensions." Industrial \& Engineering Chemistry Research 55(28): 7830-7838.

Wilberforce, T., A. Baroutaji, B. Soudan, A. H. Al-Alami and A. G. Olabi (2019). "Outlook of carbon capture technology and challenges." Science of The Total Environment 657: 56-72. 
Yang, F., X. Lee, B. K. Theng, B. Wang, J. Cheng and Q. Wang (2017). "Effect of biochar addition on short-term $\mathrm{N}_{2} \mathrm{O}$ and $\mathrm{CO}_{2}$ emissions during repeated drying and wetting of an anthropogenic alluvial soil." Environmental geochemistry and health 39(3): 635-647.

Zhang, J., Q. Xin, X. Li, M. Yun, R. Xu, S. Wang, Y. Li, L. Lin, X. Ding and H. Ye (2019).

"Mixed matrix membranes comprising aminosilane-functionalized graphene oxide for enhanced CO2 separation." Journal of Membrane Science 570: 343-354. 